\title{
Indústria 4.0: serviço social no sistema previdenciário em tempos da pandemia de COVID-19
}

\author{
Edvânia Ângela de Souza ${ }^{1,2}$ \\ https://orcid.org/0000-0002-8997-7592 \\ ${ }^{1}$ Universidade Estadual Paulista, Faculdade de Ciências Humanas e Sociais, Departamento de Serviço Social, Franca, SP, \\ Brasil \\ ${ }^{2}$ Universidade Federal de São Paulo, Programa de Pós-Graduação em Serviço Social e Política Social, Santos, SP, Brasil
}

Indústria 4.0: serviço social no sistema previdenciário em tempos da pandemia de COVID-19

Resumo: Este texto discute o cenário do trabalho de assistentes sociais (AS) da Previdência Social (PS) no Brasil, a partir da pandemia do novo coronavírus, COVID-19. Busca evidenciar como AS responderam à pandemia, em termos do seu trabalho e quais as principais mudanças ocorridas na PS nesse período. Utiliza-se de uma entrevista semiestruturada na forma de grupo focal com AS da PS. A ênfase fundamental recai sobre os processos de informatização dos benefícios previdenciários e teletrabalho correspondendo ao aprofundamento do neoliberalismo e maior fragilização do trabalho.

Palavras-chave: Pandemia COVID-19; $4^{\mathrm{a}}$ Revolução Industrial (4 $\left.{ }^{\mathrm{a}} \mathrm{RI}\right)$; Serviço Social na Previdência Social.

Industry 4.0: social work in the social security system in times of the COVID-19 pandemic Abstract: This text discusses the work scenario of social workers (SW) of Brazilian Social Security (BSS) from the pandemic of the new coronavirus, COVID-19. It seeks to highlight how SW responded to the pandemic, in terms of their work and what the main changes occurred in BSS during this period. It uses a semi-structured interview in the form of a focus group with SW of BSS. The fundamental emphasis is on the computerization processes of social security benefits and telework, corresponding to the deepening of neoliberalism and greater weakening of work.

Keywords: COVID-19 pandemic; 4th Industrial Revolution (4th IR); Social Services in Brazilian Social Security.

Recebido em: 29.06.2021. Aprovado em: 31.08.2021. Revisado em: 14.09.2021.

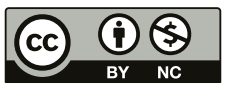

Este é um artigo publicado em acesso aberto (Open Access) sob a licença Creative Commons Attribution Non-

Commercial, que permite uso, distribuição e reprodução em qualquer meio, sem restrições desde que sem fins comerciais e que o trabalho original seja corretamente citado. 


\section{Introdução}

O princípio norteador desse texto é compreender os principais desafios colocados no contexto de trabalho do serviço social no sistema previdenciário brasileiro a partir do processo de ampla informatização dos serviços e sua transposição para ambientes remotos, aprofundado pela pandemia do novo coronavírus, COVID-19. A partir da análise de totalidade, evidencia-se que as possibilidades de mudanças e inovações tecnológicas que permitem o teletrabalho e o acesso online aos sistemas da Previdência Social (PS) antecedem às medidas de isolamento social, necessárias para conter a curva de contaminação de COVID-19. O lugar do teletrabalho, enquanto discurso e implementação prática, se deslocou rapidamente das necessidades do capital para o contexto de medida social necessária e de saúde pública, o que não elimina àquela. Se antes da pandemia a sua ocorrência era fragmentada e dispersa, após mais de um ano de pandemia, o teletrabalho ocupa a casa de $10 \%$ da força de trabalho ocupada no Brasil (IBGE, 2021).

As possibilidades de mudanças radicais no contexto de trabalho com ampla infraestrutura para a digitalização da economia e de dados da vida social, afetiva, empresarial, política e cultural (Big Data), conectividade em tempo integral, uso de Inteligência Artificial (IA) com a disseminação dos sistemas de reconhecimento de voz, uso de robôs, assistentes virtuais para os mais variados serviços, teletrabalho, entre outros (SCHWAB, 2016), comparecem na atualidade como um processo derivado da pandemia de COVID-19, até porque o isolamento social favoreceu a dependência da sociedade com a conexão em rede de internet, necessária para o convívio social, trabalho (teletrabalho), consultas médicas (telemedicina), entre outros. Todavia, o aspecto fundamental dessas mudanças é que a sua ocorrência compõe a sanha do sistema do capital pelo aumento da produtividade, das taxas de acumulação e maior controle do trabalho (MARX, 2006).

Em um breve resumo, é possível identificar que a partir da década de 1970, desenvolveu-se o processo de reestruturação produtiva associado ao neoliberalismo, à mundialização do capital e aos amplos investimentos em automação industrial e em tecnologias da informação e comunicação (TIC), produzindo as condições necessárias para o mundo contemporâneo ser, cada vez mais, conectado e muito mais capaz de efetivar os requintados e ilimitados sistemas de vigilância e de controle do capital sobre o trabalho e vida social.

As transformações desencadeadas pela Revolução Industrial, no século XVIII, foram exponenciadas a partir do aparecimento da energia elétrica, no início século XX, sendo esse o fio condutor da considerada segunda Revolução Industrial ( $\left.2^{a} \mathrm{RI}\right)$, em decorrência da ampla transformação da maquinofatura, da organização e gestão do trabalho (fordismo; taylorismo), da produção e consumo em massa, o que se estendeu para todas as dimensões da vida social, econômica, política e cultural, provocando intensas metamorfoses na produção, interior das famílias e respectivas relações, aprofundamento descontrolado da urbanização, entre outros.

A configuração do capital até os anos de 1970, mantinha a organização da produção e do trabalho voltados para a produção em massa. A crise do capital aflorada, neste período, se torna a grande justificativa para a reestruturação produtiva e para o desmonte do Estado de Bem-estar Social, erguido nos países de capitalismo avançado no pós Segunda Guerra Mundial (2 ${ }^{\mathrm{a}} \mathrm{GM}$ ) (BEHRING, 2002) subordinando o trabalho ao capital, cada vez mais sem qualquer garantias e direitos. As relações sociais de trabalho vão sendo profundamente modificadas a partir da incorporação de novas tecnologias (computacional e informacional) e de relações flexíveis de trabalho, na grande maioria dos países (HARVEY, 2006).

Com efeito, o longo desenvolvimento da flexibilização do trabalho aprofundou a subordinação, gradual e inexorável, dos países de capitalismo dependente às grandes economias mundiais. A partir da leitura de Castells (1999) é possível indicar um breve resumo das metamorfoses do Trabalho e da Sociedade assentadas no processo de organização da produção e do trabalho desencadeadas a partir da $3^{\mathrm{a}} \mathrm{RI}$ e da globalização da economia. Pois bem, considera-se um conjunto de palavras oriundas do léxico globalização: economia globalizada, empresas em rede, internet, terceirização (outsourcing), relocalização da produção, trabalho virtual, empresa mãe, filiais, fusões, incorporações de ações na bolsa de valores, cortes, desemprego, toyotismo, flexibilização, subemprego, contratos temporários, autônomos, prestação de serviços, guerra aos sindicatos, empreendedorismo, colaboracionismo, neoliberalismo, mercado financeiro, concentração de capitais, fragmentação do trabalho. A grande empresa ganha aparência de um grande escritório; a empresa matriz percorre o planeta em busca de mão de obra barata e despolitizada (CASTELLS, 1999). Os salários se resumem ao cumprimento de metas, cotas, premiações dos(as) melhores, pagamentos por resultados (BRAVERMAN, 1977). Os sistemas de controle 
foram deslocados do gerente para o interior de cada trabalhador e trabalhadora, como se fossem cúmplices da sua própria exploração, ou autoexploração (HUWS, 2017).

É importante ressaltar que as novidades do teletrabalho, trabalho mediado pelas plataformas virtuais e por por meio de aplicativos, entre outros, que ganharam visibilidade a partir da pandemia de COVID-19, não surgem com ela. Supor que tais processos são novidades trazidas pela pandemia é considerar que o mundo da produção e do trabalho estavam inalterados até então. As mudanças são radicais, sucessivas e ilimitadas. Uma visão imagética da produção e do trabalho do final do século XIX até meados do XX pode ser muito bem representada no filme Tempos Modernos, de Charlie Chaplin (1936) e, nos dias atuais, Você Não Estava Aqui, de Ken Loach (2019).

A fábrica povoada de trabalhadores alinhados à esteira e imersos ao trabalho repetitivo vai se configurando em cenas de trabalhadores(as) mais esparsos, fragmentados, dispersos em casa na frente de uma tela de computador ou reunidos por um aplicativo.

Neste contexto, o tempo de trabalho, o tempo produtivo embrenha-se no tempo livre e no tempo da reprodução social. Aprofundam-se a subsunção real e formal do trabalho ao capital (MARX, 2006). O trabalho não se limita mais apenas a um espaço específico, mas gravita por todos os poros da vida social. Comemorase que já não há mais o controle da jornada de trabalho. Não há controle? A gestão do trabalho deixou de ser exercida por um feitor ou um gerente para ser assumida pelos trabalhadores e trabalhadoras, que numa relação dialética, são produtorela(s) livres de relações potencialmente servis, como tão bem explicita o filme Você Não Estava Aqui (2019), de Ken Loach. Greves e sindicatos são vistos como ações retrógradas e dispensáveis, pois o imperativo social da força de trabalho deve se pautar unicamente pela filosofia do empreendedorismo individual, vista como verdadeiro meio para melhorar a condição de vida. Embuguersamento, angústia e medo, são sentimentos comumente relatados por quem adoece devido a pressão no trabalho (LOURENÇO, 2016).

A partir de finais do século XX, as empresas já estão embrenhadas em amplo processo de modernização para a produção globalizada, garantida por meio de uma nova infraestrutura de automação industrial, Tecnologias de Informação e Comunicação (TIC) e, entre outros, pelas novas modalidades de gestão da produção toyotizada e do trabalho flexível (HARVEY, 2006; HUWS, 2017; ANTUNES, 2018).

Essas linhas introdutórias apresentam um conjunto complexo de questões que entram na ordem do dia em tempos da pandemia de COVID-19, mas a contextualidade da estrutura social, econômica, política e cultural mediada pela ampla digitalização e conexão em redes de internet atestam que a sua origem é resultado do capitalismo maduro e desenvolvido e não como resultado diretos da pandemia. Marx (2006) já havia afirmado que o capitalismo para sobreviver necessita de realizar constantes transformações, ou seja, é necessário se revolucionar constantemente, sendo esse o seu caráter universal para a maximização da produtividade, da acumulação e da manutenção do seu poder e ideologia. Portanto, o desenvolvimento e difusão das TIC, especialmente, a partir do final do século XX, 1990, sedimentou os paradigmas tecnológicos atuais, uma vez que a produtividade, a capacidade de circulação das mercadorias, o trabalho e a vida sociocultural estão cada vez mais dependentes das tecnologias de informação. Tratam-se de mudanças profundas do modo de organizar e gerir o trabalho, a produção e a circulação, num modelo econômico que prioriza acionistas, portanto, ainda que em momentos de crise, as grandes empresas mantém os repasses aos acionistas (OXFAN, 2020, P. 18-19).

Enquanto isso, a pandemia de COVID-19 agravou ainda mais os níveis de emprego, com profundos impactos para os níveis de civilidade, o que poderá elevar a situação de pessoas vivendo em situação de pobreza em até meio bilhão, mais de 400 milhões de pessoas, na maioria mulheres perderam os seus empregos (OXFAN, 2020). No Brasil, a taxa de desocupação em 2020, atingiu 13.8 milhões de pessoas (IBGE, 2021), com forte impacto sobre a população preta, especialmente, mulheres. Paradoxalmente, os direitos que parecem estar muito mais acessíveis, uma vez que o Estado vem realizando investimentos para o seu acesso online, na realidade, estão cada vez mais distantes e restritos.

Neste contexto, vem sendo indicados sérios impactos para o trabalho (ANTUNES, 2018; ABÍLIO, 2019) e intensificação do estranhamento social. Han (2018) destaca que o fenômeno das redes e mídias digitais, marcado pelo anonimato, distanciamento e emoção que as mensagens suscitam, aglutinam indivíduos numa espécie de "enxame" em torno de determinado assunto, sem maiores aprofundamentos e responsabilidades provocam verdadeiras desestabilizações sociais, se dispersando de forma tão rápida quanto da sua formação (HAN, 2018), o que vem afetando profundamente as democracias. 
Portanto, a partir dessa incursão introdutória, busca-se discutir o trabalho de assistentes sociais (AS) da PS brasileira, com foco específico as mudanças desencadeadas pela pandemia de COVID-19.

\section{Método}

Este texto está subsidiado no estudo bibliográfico e coleta de dados empíricos por meio de uma entrevista semiestruturada, na forma de grupo focal (GF), com assistentes sociais (AS) de uma Gerência da PS, localizada em uma cidade do estado de São Paulo, próxima à capital paulista. O GF ocorreu em agosto de 2020, por meio de plataforma on line, com a participação de quatro AS de diferentes Agências da Previdência Social (APS) pertencentes a uma determinada Gerência da PS. O GF seguiu as normas éticas em pesquisas, conforme projeto de pesquisa mais amplo, que se encontra em andamento ${ }^{1}$.

\section{$4^{a}$ Revolução Industrial ( $\left.4^{a} \mathrm{RI}\right)$ e o aprofundamento da acumulação de capitais versus perda de direitos e fragmentação do trabalho}

$\mathrm{O}$ uso de computadores e demais incrementos da $3^{\mathrm{a}} \mathrm{RI}$, acompanhados de intensas mudanças no mundo do trabalho e sociedade, em fins do século XX, adquirem novas expressões a partir de amplos investimentos públicos em tecnologias de ponta, especialmente por parte dos Estados Unidos da América (EUA), China, Alemanha e Japão, com o objetivo de maior controle geopolítico, efetivado mais especificamente a partir da primeira década do século XXI (FERNANDES, 2019), configurando a 4a Revolução Industrial (4ª RI) (SCHWAB, 2016).

O ciberespaço e demais tecnologias mediadoras do mundo informatizado, Inteligência Artificial (IA), Big Data, Internet das Coisas (IoT), entre outras, que há muito já não se limitam mais apenas aos computadores, mas vão além dos smartphones e notebooks a objetos inteligentes, que estão integrados em realidade virtual, simulações, aplicação de ships em humanos, acesso a dados pessoais pelo poder empresarial e político sem a necessidade de autorizações etc. (ROCHA, 2019).

A 4 ${ }^{\mathrm{a}} \mathrm{R}$ ou Indústria 4.0 não se reduz a sistemas avançados de informação, automação e computação, a partir do uso de software, sensoriamento e conexão na internet, mas se nutre de amplas pesquisas e financiamentos em neuromodelação, neurotecnologia, biotecnologia, que visam tornar a espécie humana mais inteligente e adaptada, cujas modificações avançam para sobrepor os limites biológicos e orgânicos do ser humano para o trans-humano futuro, com base na evolução cultural das tecnologias (FERNANDES, 2019).

Fernandes (2019) chama a atenção para os investimentos bilionários no ramo do chamado melhoramento humano e nos laboratórios de pesquisas transhumanistas no Vale do Silício, nos EUA, que visam a superação da inteligência humana pela artificial e a sua fusão, com vistas a criação de seres humanos híbridos e também a ascensão na divisão geopolítica, de domínio e controle global (FERNANDES, 2020). Graham (2016) mostra o aumento do controle do capital sobre a vida humana e meio ambiente nas mais variadas regiões do mundo, em decorrência da capacidade de o capital se apropriar da imensa quantidade de dados que são produzidos voluntariamente por amplas parcelas da população no mundo, sendo que tecnologias específicas de inteligencia artificial são utilizadas para mineração desses dados e uso a partir dos objetivos da economia neoliberal, do "livre mercado" e indústria bélica apoiada em sofisticados aparelhos de vigilância e de extermínio, cada vez mais, efetuados por meio dos drones (GRAHAM, 2016).

Couchot, Tramus e Bret (2003) destacam que em 1950, quando dos princípios da vida artificial, o matemático John Von Neuman perguntou se uma máquina poderia duplicar a si mesma e se essa cópia poderia ser mais elaborada que a original e propôs uma teoria matemática sobre os autômatos auto-reprodutores (COUCHOT; TRAMUS; BRET (2003). Nesse mesmo período, Turing (1950) questionou se as máquinas pensam e, mais ainda, se valeria a pena investir na construção de máquinas pensantes. A máquina inteligente ou a máquina pensante seria capaz de dar respostas sem ser vista e em tempos recordes, em contraponto com o ser humano que necessita de mais tempo e de amplo processo de formação para responder à determinadas perguntas, além disso, conta com impressionante defasagem e imprecisão aritmética, Turing (1950). O autor propôs que uma máquina pudesse ser construída para jogar o jogo da imitação de forma satisfatória, não se 
trata de um ser humano aprimorado biologicamente, mas de uma máquina capaz de aprender, já especificada por ele, a partir de computadores (TURING, 1950). São as primeiras incursões para o desenvolvimento da Inteligência Artificial (IA).

Em resumo, observa-se que, desde meados de 1950, Neuman questionou a evolução das máquinas consideradas como uma espécie viva e Turing (1950) mostrou que um computador poderia assumir atividades de aprendizado, como se pudessem pensar, desde que seguissem as condições previamente estabelecidas pelos humanos.

As operações na internet estão num processo contínuo de produção de dados, sobre os quais a autonomia de seus proprietários originais (usuários(as)) é quase nula, pois se tornam estratégias comercializáveis (ZUBOFF, 2018). Portanto, "[...] o big data é, acima de tudo, o componente fundamental de um nova lógica de acumulação, profundamente intencional e com importantes consequências, que chamo de capitalismo de vigilância (ZUBOFF, 2018, p.18).

Para Graham (2016) o uso de dados produzidos pela alta tecnologia, tais como os sistemas de rastreamento e de vigilância do mundo moderno que alimentam o lucrativo mercado de exportação das inovações da indústria bélica e de sistemas informatizados de segurança e de defesa criam um novo urbanismo militar, cujo poder é centralizado nas elites das "cidades globais", de onde são orquestradas as medidas do capitalismo neoliberal para as "regiões colonizadas". "[...] Londres, Nova York, Paris Frankfurt e assim por diante - ajudam a produzir novas lógicas de desapropriação e aquisição colonial agressiva pelo capital multinacional, que opera em proximidade com exércitos e empreiteiras multinacionais (GRAHAM, 2016, p. 38).

Chamayou (2015) inicia a sua obra com o diálogo entre operadores de drones nos EUA com ações no Afeganistão. Trabalhadores que estão na base de Creech, berço da frota de drones da US Air France, localizada nas proximidades de Indian Springs, em Nevada, ou seja, estão distantes do campo minado de uma guerra, trabalham em escritórios, completado o turno de trabalho podem sair tranquilamente e juntar-se aos seus.

Cumpre repetir aqui um trecho do diálogo descrito por Chamayou (2013):

Você pode dar um zoom? Quero dar uma olhada.

Pelo menos quatro atrás da picape.

- E esse cara, debaixo da flecha norte, parece que ele tem uma coisa no peito.

- É, é meio estranha a mancha fria que eles têm no peito.

$[\ldots]$

O coordenador: O screener disse que há pelo menos uma criança perto do 4 X4.

$[\ldots]$

O operador: Envie-me uma porra de um clichê, mas não acho que têm crianças a essa hora, sei que eles são barra pesada, mas não precisa exagerar.

$[\ldots]$

O piloto: Então, verifiquem essa merda... Por que ele não disse "possível criança" então? Por que têm tanta pressa de falar de porras de crianças mas não de porras de armas?

$[\ldots]$

$1 \mathrm{~h} 50$

O coordenador: Adolescente perto da traseira do 4 X 4 .

O operador: Ah, bom adolescentes podem lutar.

[...] o drone Predador tem apenas um único míssel a bordo - insuficiente para atingir três veículos -, é dada a ordem a dois helicópteros Kiwoa, nome de código "BamBam 41", que se ponham em posição para ataque. Um plano é aprovado ... (CHMAYOU, 2013, p. 5- 17).

Chamayou (2015) evidencia que o plano de ataque é aprovado, o qual é efetuado, sem qualquer risco físico para os operadores, pilotos de drones e demais trabalhadores envolvidos na operação em que atuam a partir de uma base, um local mais próximo a uma escritório que a um campo de guerra. Em primeira mão está a capacidade de vigilância e ação violenta perpetrada a milhas e milhas de distância. A capacidade de enxergar à distância, dar um zoom, inspecionar e identificar detalhes, como a marca do carro; a xenofobia, especialmente nos dizeres: a coisa fria que eles têm no peito, a ideia introjetada que são potencialmente alvos porque representam riscos à segurança nacional; a ideia de terrorismo sem preservar civis, crianças e a visão 
que adolescentes são combatentes e a definição de ataques a milhas e milhas de distância, a partir de ambientes seguros. Tudo se passa como se fosse um jogo, um game.

Chamayou (2015) evidencia que são cada vez mais rotineiro o uso de drones, sendo que nos EUA já se formam mais operadores de drones que pilotos de avião e vem ocorrendo a dronização das forças armadas americanas.

Crary (2016) evidencia os gastos frequentes e elevados com ações militares por meio de operações robóticas e remotas, contudo, frisa que ainda serão necessários grandes contingentes humanos para as necessidades bélicas: “[...] haverá ocasiões em que... drones armados com mísseis não poderão ser empregados, e esquadrões da morte com soldados resistentes ao sono e à prova de medo serão necessários para missões de duração indefinida (CRARY, 2016, p. 13-13).

Observa-se que estão sendo criadas as condições para o trabalho 24 horas durante sete dias da semana, capitalismo de vigilância, dones, armas não tripuladas, carros autônomos, ships, melhoramento genético, Inteligência Artificial, Big Data, teletrabalho, trabalho virtual, trabalho por app, plataformização, ensino remoto, home office, entre outras palavras que vão se popularizando a partir do léxico da $4^{\mathrm{a}} \mathrm{RI}$ e radicalizando as condições pré existentes para o controle social e do trabalho e maior acumulação capitalista. No oposto, o processo de trabalho se individualiza e se efetiva por meio da prestação de serviços precedidas por cadastros em plataformas on line, cujas atividades dependem dos meios fornecidos pelos próprios trabalhadores e trabalhadoras, que passam a adquirir os meios de trabalho e a estabelecer as melhores estratégias, horários e habilidades para os seus rendimentos, o que Abílio (2019) denominou de autogerenciamento.

\title{
Trabalho, serviço social e PS em tempos de pandemia da COVID-19
}

\author{
Criar meu web site \\ Fazer minha home-page \\ Com quantos gigabytes \\ Se faz uma jangada \\ Um barco que veleje... \\ (Pela Internet, Gilberto Gil, 1997)
}

Há mais de vinte anos, o cantor Gilberto Gil representou por meio da canção Pela internet, no álbum Quanta, de 1997, a qual ganhou nova versão em 2018, Pela Internet 2, o deslocamento das relações presenciais e ações concretas da vida real para o ambiente virtual, repleta de informações, $e$-comerce, redes sociais etc: "Estou preso na rede. Que nem peixe pescado. É zapzap, é like. É instagram, é tudo muito bem bolado (Gil, 2021). Como esse processo de avanço de inovações tecnológicas comparece no processo de trabalho no sistema de PS?

O Instituto Nacional de Seguro Social (INSS) já vinha com um processo de restruturação do atendimento ao público e respectivo trabalho a partir da presença das TIC, pelo menos desde 2017, quando da implementação de sistemas on line para o acesso remoto e a criação de um projeto piloto para o teletrabalho. Assim, a pandemia de COVID-19 acelera e adensa esse processo, tal como resume bem a criação do robô Helô, um robô virtual IA, capaz de reconhecer necessidades de usuários que interagem com o site Meu INSS e de identificar possíveis respostas a partir dos sistemas de dados informatizados. O traço básico desse processo é o atendimento feito por uma máquina em ambiente virtual, como se fosse uma lógica independente do trabalho humano ou da intervenção e práxis social. Ademais, cria-se uma enorme capacidade de controle dessas informações. Os dados estão sendo armazenados em uma estrutura muito dinâmica, cuja vinculação essencial entre esses bancos de dados (Big Data) e os sistemas de IA é a incrível possibilidade de cruzar dados com outros sistemas, quando inúmeras decisões podem sobressair desse processo para fins alheios aos do momento em que a pessoa forneceu as informações, na especificidade da PS, é possível o cruzamento de dados para justificar os indeferimentos de pedidos de benefícios.

Então, primeiro é que é algo novo pra todo mundo..., mas a gente teve que reestruturar as nossas atividades. O que que eu, particularmente, estou fazendo de trabalho no período da pandemia? é... o INSS publicou uma normativa que os Benefícios de Prestação Continuada (BPC), que estavam represados por conta da 
avaliação social e perícia médica, que dependem do atendimento presencial, foi feito uma antecipação de $\mathrm{R} \$ 600,00$ em três meses pra esses beneficiários. Então, é... foi algo que não foi muito divulgado, então, a gente fez essa busca ativa desses casos por meio de contatos com a rede. Esse foi um dos trabalhos que nós fizemos. Bastante assessoria à rede, que também ficou com muita demanda nesse sentido. E, por último, em relação à reabilitação profissional, que também foi normatizado o atendimento à distância... $\mathrm{Na}$ verdade, a gente tem entrado em contato com os segurados que cada uma acompanha para orientar sobre os encaminhamentos nesse período de pandemia. Nós, que estamos na Agência, o trabalho tem sido esse: assessoria à rede, busca ativa dos casos de BPC com antecipação, que não são todos, orientação e acompanhamento da reabilitação profissional (GF com AS da PS).

Nós temos recebido muitas dúvidas, eu vou citar em relação a 'como solicitar o auxílio doença com atestado médico’, para a antecipação, né. Então, as perícias presenciais não estão acontecendo... foi criado, no site Meu INSS, um espaço onde a pessoa pede a perícia médica e anexa uma cópia do RG e atestado médico. Essa antecipação do auxílio doença, nesse período de pandemia, é no valor de um salário mínimo mesmo que o benefício do segurado seja maior, nesse caso, a diferença pode ser paga depois, quando retomarem os atendimentos presenciais e o segurado passar pela perícia presencial. Então, essa antecipação, é concedida por um mês, se a pessoa precisar de novo, ela tem que pedir prorrogação, se concedida, é no valor de um salário mínimo (GF com AS da PS).

O trabalho profissional do serviço social na PS se realiza a partir de atendimentos e orientações com forte presença junto à rede de serviços e políticas sociais, com vistas à ampliação do acesso aos direitos previdenciários, na defesa dos direitos das pessoas com deficiência, idosos, trabalhadores e trabalhadoras da área rural, saúde do trabalhador e da trabalhadora, entre outros (BRAGA; CABRAL, 2007; SOUZA, ANUNCIAÇÃO, 2020).

A pandemia de COVID-19 é algo novo pra todo mundo e de fato é uma catástrofe inesperada para o mundo, todavia a possibilidade de o INSS ter reestruturado as suas ações para o trabalho remoto e o acesso digital ao sistema previdenciário, implica considerar as condições pré existentes, ou seja, não é a pandemia de COVID-19, que cria o trabalho remoto, todavia, com ela, há a sua intensificação, uma vez que a necessidade de isolamento social e de afastamento do trabalho presencial das pessoas acima de 60 anos de idade ou com comorbidades, acelerou o processo de teletrabalho, home office e o acesso aos benefícios por meio de plataformas digitais.

Os pedidos online para o Benefício de Prestação Continuada (BPC) e Auxílio Doença tiveram a antecipação do pagamento, devido a impossibilidade de se realizar a avaliação social e médica presencialmente, o programa de reabilitação profissional também passou a ser feito de forma remota. As solicitações têm ocorrido por meio da plataforma Meu INSS. A antecipação do BPC garante o pagamento de R $\$ 600,00$ (seiscentos reais), exige, entre outros, o cadastro no CadÚnico como pessoa com deficiência e também é necessário estar em conformidade com o critério da renda, per capita de até $1 \frac{1}{4}$ do salário mínimo (BRASIL, [2021]). O Auxílio Doença, diferentemente do BPC, é um benefício específico da pessoa que é segurada pelo sistema previdenciário, ou seja, apenas segurados têm esse direito, o qual também passou a ser solicitado por meio de plataforma on line, com a exigência de solicitações mensais, o valor antecipado é de um salário mínimo, independente se $o$ (a) segurado ou segurada contribui com um valor mais alto.

Quando se fala em acesso aos benefícios sociais por meio de plataformas online, é preciso considerar as condições de acesso à internet de grande parte da população brasileira. Pesquisa realizada pelo Centro Regional de Estudos para Desenvolvimento da Sociedade da Informação (Cetic), em 2019, identificou que 46 milhões de brasileiros(as) não tinham acesso à internet, sendo $37 \%$ dessas pessoas não tinham acesso porque também não tinham celular, computador ou tablet (RAQUEL, 2020). Embora, os dados indiquem que $71 \%$ das residências, 134 milhões de pessoas, tinham internet em 2019, é reportado também que uma pessoa de cada cinco que tem internet toma emprestado da rede do vizinho. Além disso, a internet ainda é pouco frequente na zona rural (RAQUEL, 2020). Outro vetor é que o acesso à internet se dá predominantemente via celular, $58 \%$, a pesquisa evidencia que vem caindo o acesso a computadores, notebook e tablets (RAQUEL, 2020).

... complicada, é que a grande maioria dos segurados acaba por não conseguir usar a internet. Então, muitas vezes, eles recorrem a uma Lan House, às vezes, ao CRAS [Centro de Referência em Assistência 
Social] e intermediários, sejam eles advogados ou não... Então, é difícil, na hora que precisa o acesso é complicado....(GF com AS da PS).

[...] Às vezes, entre um atendimento e outro, você conversa com a pessoa, pergunta: 'você tem internet?' 'não'; 'você é atendido no CRAS?' 'não'; 'você tem filhos que podem te ajudar a acessar o sistema? 'não', a maioria ainda fala: 'eu já tentei cadastrar senha e não consigo' ... Isso tem gerado vindas até aqui na Agência, que está fechada, mas estou trabalhando internamente, eles ligam na Agência e falam: "eu preciso da sua ajuda, estou aqui na porta, não sei fazer...” (GF com AS da PS).

As entrevistadas evidenciaram as dificuldades que a população encontra para acessar os seus direitos por meio das plataformas digitais, especialmente, quando da necessidade de operacionalizá-los nos sistemas online, que exigem determinadas habilidades, conhecimentos das legislações e condições materiais, tais como acesso à internet, aparelhos compatíveis etc.

As mudanças tecnológicas poderiam ser entendidas como sinais de níveis elevados de bem-estar social e maior qualidade de vida da população, contudo, isso não ocorre de forma homogênea, haja vista que a sociedade do capital é uma sociedade marcada pela exploração do trabalho e ampla desigualdade de acesso aos bens socialmente produzidos. Marx (2006) evidencia que o sistema de produção do capital é um sistema antagônico, cuja reprodução social, reproduz também os antagonismos sociais; a miséria que atinge grande parte da população é proporcional ao volume da acumulação do capital, que fica restrita aos poucos grupos detentores do poder econômico e político.

Os avanços da técnica e da ciência cabem mais aos interesses de acumulação do capital que ao atendimento das necessidades humanas, sejam elas físicas ou espirituais (MARX, 2006). Portanto, as relações sociais de produção, tendencialmente, são relações que alienam homens e mulheres, cujos objetos e invenções socialmente produzidos se autonomizam, confrontando os seres humanos, numa evidente inversão de domínio entre sujeito e objeto, são relações historicamente reificadas.

A ausência de computador, notebook ou celular e conexão à internet para acessar o sistema da PS, coloca parcela dos usuários e usuárias em busca de orientação e apoio nos espaços dos Centros de Referência de Assistência Social (CRAS) e nas APS, pois ainda que com as medidas de isolamento social, como referenciado por uma das AS entrevistadas, as pessoas ligam ou vão até as Agências, ainda que essas estejam fechadas para o atendimento ao público.

De fato, as mudanças radicais que ocorrem para o acesso virtual dos benefícios previdenciários exigem condições materiais e habilidades técnicas, que são transferidas para os usuários e usuárias, que por sua vez recorrem ao serviço social das políticas da assistência social ou previdência social para contar com o apoio para o acesso ao sistema e efetivar os pedidos: "muito às vezes, fica difícil para uma pessoa criar uma senha e pedir para escanear um documento e anexar no sistema, muito, muito complicado" (GF com AS da PS). Assim, foi referenciado também que muitas pessoas acabam contando com a "ajuda" de atravessadores, advogados para cadastros, encaminhamentos de documentos e acesso on line aos benefícios da PS, onerando ainda mais essas pessoas.

As atividades são parecidas com o que as meninas já falaram, mas eu não estou em teletrabalho Mas, o que dificulta? Eu não tenho acesso ao sistema, só quem está na Agência ou no teletrabalho que acessa. Então, o que eu consigo fazer em casa? Somente os atendimentos à distância da reabilitação, que foi liberado pelo WhatsApp e os atendimentos da rede que também é pelo WhatsApp... Mas veja, tudo que eu vou fazer praticamente eu necessito do sistema, então, não consigo porque não tenho acesso. Às vezes, conto com o apoio das meninas que estão na Agência, trabalhando internamente, pra fazer consultas ao sistema e me ajudar a responder algum e-mail ou alguma mensagem... (GF com AS da PS).

VPM é o sistema. Eu tenho acesso ao VPM, mas não foi autorizado pra todos. Na nossa Agência não são todos que têm acesso, só quem está no teletrabalho, os demais não. Esse acesso, que é do sistema interno do INSS... não adianta, porque não tem outra forma de se conectar, eles têm que autorizar esse sistema pra gente utilizar, entendeu?" (GF com AS da PS). 
As entrevistas permitem identificar diferentes regimes de trabalho entre AS da PS, uma vez que há o teletrabalho, que com a pandemia de COVID-19 foi amplamente instituído pelo INSS, sobretudo, para os servidores e servidoras do setor administrativo da Previdência, sendo que parte das AS também aderiram, neste caso, assumiram atribuições e competências que não são do serviço social e que se relacionam a habilitação de benefícios. O serviço social, quando do fechamento das APS ficaram trabalhando internamente nas Agências para orientações gerais ou em casa, em home office, sendo esse regime de trabalho muito diferente do teletrabalho, que é mediado por novas tecnologias, novos métodos de gestão e de remuneração. Em outro texto, desenvolveu-se o tema do teletrabalho na PS (SOUZA, 2021).

O trabalho do serviço social da PS em home office foi organizado a partir de "plantões", para contatos com rede socioassistencial, orientações por e-mails, contatos telefônicos e troca de mensagens de WhatsApp. "Ah, nós estamos em muitas situações trabalhando no plantão, algumas em casa, outras na Agência, assim, atendemos as inúmeras dúvidas dos segurados e também da rede por meio do contato telefônico, WhatsApp e e-mails" (GF com AS da PS).

O acesso aos sistemas intranet do INSS fora das Agências da PS, que uma das entrevistadas denomina de VPM, ficou limitado aos servidores e servidoras do setor administrativo em teletrabalho, para análises dos pedidos de benefícios, não sendo liberado ao serviço social. Cabe registrar que historicamente o serviço social na PS tem protagonizado importante movimento de lutas e resistências para a sua permanência nas APS e também para a garantia do trabalho profissional a partir das suas atribuições e competências (LEA; CABRAL, 2007). Contudo, ao trabalhar em casa, AS informam as dificuldades postas pela impossibilidade de acessar o sistema intranet do INSS, o que é necessário para muitas informações e orientações, sendo que "em casa, são poucos os sistemas que a gente consegue acessar, sem o VPM, é bem mais limitado" (GF com AS da PS).

Em relação ao teletrabalho, AS evidenciaram a introdução de novas metodologias de gestão do trabalho pelo INSS, com incidência para o pagamento por produtividade. "É, no teletrabalho, cada atividade que você faz tem um ponto, então, é por bônus..." (GF com AS da PS).

O teletrabalho que no discurso do senso comum e empresarial é um trabalho mais livre, autônomo e feito em casa, se configura como um tipo de trabalho altamente mensurável, cada atividade tem uma pontuação, sendo a liberdade cada vez mais substituída pela necessidade constante de atingir os pontos especificados pela gestão.

Em primeiro lugar, eu ando tão, é... tão sem perspectiva, que não vejo problema em divulgar o meu nome na pesquisa, não tenho problema nenhum. Muito sem perspectiva e sem qualquer possibilidade de que a Previdência vá ter alguma mudança, né. Então, pelo que a colega falou, nós temos parte da equipe, né, que tá em trabalho remoto. Eu tenho um filho de seis anos de idade, mas eu não aderi ao trabalho remoto, devido às questões mesmo de... das cobranças institucionais, por isso, permaneci trabalhando na Agência (GF com AS da PS).

Ao tematizar a questão do teletrabalho é preciso considerar a complicada conjunção de variáveis determinadas por um evento muito particular, a pandemia de COVID-19 e, em consequência, a inviabilidade do trabalho presencial. Esse é um fato. Todavia, pelo menos três anos antes da pandemia, o INSS já vinha realizando os investimentos necessários para o teletrabalho e o acesso online aos sistemas, cujo alcance e significados históricos decorrem das inovações tecnológicas de computação avançada, IA e Big Data que repõem elementos qualitativamente novos para a organização e gestão do trabalho.

Com efeito, para reter apenas em alguns dos elementos destacados pelas AS entrevistadas, sintetiza-se que o teletrabalho é uma estratégia de intensificação laboral, pois ao ser feito em casa, apesar de supor maior liberação das exigências institucionais, na realidade, é mediado por maior nível de cobrança, como dito pela AS que preferiu se manter trabalhando na Agência que ficar em home office ou teletrabalho. Mas nem sempre é possível escolher. AS relataram que a gestão do INSS vem reiteradamente buscando inserir o serviço social na reestruturação das Agências, o que envolve o teletrabalho e o trabalho por produtividade "[...] nós temos a noção, vemos isso no dia a dia, agora é difícil resistir porque chega como imposição mesmo" (GF com AS da PS).

Ao estabelecer o teletrabalho, o INSS criou também os scores de produtividade para avaliação do trabalho vinculada ao pagamento. Ademais, para garantir o cumprimento das metas, introduziu também a competência dos investimentos em condições, instrumentos de trabalho e internet de maior alcance para os servidores e servidoras. A novidade é que são os próprios trabalhadores e trabalhadoras que passam a investir nos meios para efetivar o processo de trabalho, responsabilidade até então a cargo da empresa. O teletrabalho 
exige mais das mulheres em decorrência da histórica divisão sexual do trabalho, em especial, nesse período de fechamento das escolas, aulas remotas etc, o que acaba elevando a jornada de trabalho das mulheres, tornando o ambiente doméstico um ambiente de estresse, como afirmado pela AS, que preferiu se manter trabalhando na APS que ficar em home officce.

$\mathrm{O}$ teletrabalho condiciona o trabalho à individualização. O trabalho fora da Agência quebra a possível solidariedade e relações de apoio e de amizade originárias dos ambientes de trabalho, a curto prazo, tenderá para a perda de direitos, ausência de concursos públicos e avanço das contratações terceirizadas.

Então, dá impressão, né, pra instituição, que os trabalhadores estão trabalhando menos em casa, mas, não é assim, têm que fazer mil planilhas, análises e tem que seguir pontuações exigidas, não é livre...

Sabe? É uma situação de sofrimento, que eu... É, eu, particularmente, tenho sofrido muito, porque a pandemia, ela já trouxe um arraso absurdo na vida dos trabalhadores em todos os sentidos e a gente vê isso, ou melhor, a gente sente isso... também trouxe mais exigências para nós também e fica a insegurança, e pós pandemia? (GF com AS da PS).

O contexto pandêmico traduz muitas incertezas para a vida social e para a classe trabalhadora que passa a vivenciar significativa redução dos seus ganhos, insegurança no trabalho, pressão, o que reverbera em sofrimento no/pelo trabalho, que não será aprofundado nesse texto, mas é um tema contingente entre AS da PS e, portanto, revelador das condições e subjetividade no trabalho.

\section{Considerações Finais}

O Estado neoliberal revela uma visceral incapacidade para enfrentar os conflitos entre capital e trabalho, estando fundamentado e reorganizado a partir dos parâmetros exigidos pelo capital financeiro internacional, estabelece em âmbito nacional, não apenas as medidas que reduzem os direitos sociais ao limite, mas recria um movimento específico do autoritarismo, conservadorismo com traços marcantes do fascismo. Dessa forma, o Estado neoliberal imputa a violência contra os insurgentes, desvalidos e marginalizados dos grandes centros urbanos e interior, revelando a sua face violenta, que no Brasil, se intensifica a partir da questão étnico-racial e genocídio dos jovens negros, tal como o massacre de Jacarezinho, Rio de Janeiro em cinco de maio, de 2021, que exterminou quase três dezenas de jovens (MATA, 2021).

A pandemia de COVID-19, no contexto sócio histórico da revolução digital, impõe uma dinâmica própria ao funcionamento dos serviços e a operacionalização do trabalho a partir da compressão dos espaços físicos e presenciais que são transfigurados para o ciberespaço e de mudanças engendradas pelas estruturas neoliberais. $\mathrm{O}$ trabalho fica comprimido aos encontros virtuais e à realização de tarefas limitadas às plataformas digitais. Deste modo, o trabalho coletivo e a solidariedade em espaços de trabalho tendem para as trocas feitas por meio de grupos de WhatsApp, ou salas de reuniões virtuais, sem desconsiderar a importância desses mecanismos, que contribuem para a troca de ideias e organização coletiva de trabalhadores e trabalhadoras. Todavia, há de frisar a necessidade do resgate daquilo que conforma o trabalho coletivo, a saber: estar junto, se encontrar no espaço de trabalho, trocar informações e discutir a respeito das mudanças nos processos de trabalho, remuneração e condições de trabalho para além da operacionalização de sistemas, mas buscar estratégias para frear a destruição e limitação dos direitos, o que recai também para o engajamento político junto à classe trabalhadora. Atualmente, está em fase de aprovação a Proposta de Emenda à Constituição (PEC), no. 32, que afeta especialmente os direitos, a estabilidade e os concursos públicos. A defesa dos direitos dos funcionários e funcionárias do setor público exige união entre as mais variadas categorias e segmentos da classe trabalhadora porque se trata, em nível mais amplo, da defesa dos direitos sociais. O debate das questões candentes do trabalho e dos serviços públicos interatua para o processo de formação da consciência crítica de classe e para o enfrentamento da complexidade do trabalho, que em tempos de pandemia de Covid-19, não está isento da fragilização e do avanço do neoliberalismo.

Por fim, fica o questionamento de como se processará o trabalho profissional do serviço social no período pós-pandemia. O conjunto de inovações em torno das TIC, o acesso dos benefícios por meio de plataformas 
digitais não serão interrompidos, mas, certamente, serão constantemente aprofundados, o que impõem novos desafios ao trabalho profissional em ambientes tão fortemente mediados pelas plataformas digitais.

\section{Referências}

ABÍLIO, Ludmila Costhek. Da revenda dos produtos da Natura ao motorista Uber: a generalização do trabalho informal: entrevista com Ludmila Costhek Abílio, 2019. Fórum de Debates e Entrevistas: Saúde do trabalhador e da Trabalhadora e Serviço Soicial. Disponível em: https://www.youtube.com/watch?v=9Qx_VUWMl6w. Acesso em: 5, mar. 2020.

ANTUNES, Ricardo. O Privilégio da Servidão: o novo proletariado de serviço na era digital. São Paulo: Boitempo, 2018.

BEHRING, Elaine Rossetti. Política Social no Capitalismo Tardio. 2. ed. São Paulo: Cortez, 2002.

BRAGA, Léa; CABRAL, Maria S. R. (Orgs.). Serviço Social na Previdência: trajetória, projetos profissionais e saberes. São Paulo: Cortez, 2007.

BRASIL. Lei $n^{\circ}$ 13.982, de 2 de abril de 2020. Brasília DF: Presidência da República, [2021]. Disponível em: http://www.planalto. gov.br/ccivil_03/_ato2019-2022/2020/lei/113982.htm. Acesso em: 5, set. 2020.

BRAVERMAN, H. Trabalho e capital monopolista: a degradação do trabalho no século XX. Rio de Janeiro: Zahar, 1977.

CASTELLS, M. A Sociedade em Rede. São Paulo: Paz eTerra,1999.

CHAMAYOU, G. Teoria do Drone. São Paulo: Cosac Naify, 2015.

COUCHOT, E.; TRAMUS, M.; BRET, M. A segunda interatividade, em direção a novas práticas artísticas. DOMINGUES, D. (Org.). Arte e vida no século XXI. São Paulo: editora Unesp, 2003, p. 27 -38.

CRARY, J. 24/7: capitalismo tardio e os fins do sono. São Paulo: Ubu Editora, 2016.

FERNANDES, V. C. R. A distopia empírica do capitalismo digitalizado: novas formas de controle, reordenamento econômico, político e social no marco da Indústria 4.0. In: SOUZA, E. A.; SILVA, M. L. O. Trabalho, questão social e Serviço Social: a autofagia do capital. São Paulo: Cortez, 2019. p. 61-73.

GRAHAM, S. Cidades Sitiadas: o novo urbanismo militar. São Paulo: Boitempo, 2016.

HARVEY, D. Condição pós-moderna: uma pesquisa sobre as origens da mudança cultural. 15. ed. Rio de Janeiro: Edições Loyola, 2006. GIL, Giberto. Pela Internet 2. Disponível em: https://gilbertogil.com.br/conteudo/musicas/?letra=P. Acesso em: 12, mai. 2020.

Quanta, 1997. Disponível em: https://gilbertogil.com.br/producoes/detalhes/quanta/. Acesso em: 12, mai. 2020.

HUWS, U. A formação do cibertariado. Campinas: Editora da UNICAMP, 2017.

IBGE. Instituto Brasileiro de Geografia e Estatística. Desemprego. Disponível em: https://www.ibge.gov.br/explica/desemprego.php. Acesso em: 26, jun. 2021.

LOURENÇO, Edvânia Ângela de Souza (Org.). Saúde do/a trabalhadorla e Serviço Social: estudos da relação trabalho e saúde no capitalismo contemporâneo. São Paulo: Papel Social, 2016.

MARX, K. O Capital: crítica da economia política: Livro I: o processo de produção do capital. São Paulo: Boitempo, 2006.

MATA, J. da. Jacarezinho: favela palco de massacre nasceu como quilombo, lutou contra a ditadura e hoje é refém da violência. $B B C$ News, Rio de Janeiro, 22 maio 2021. Disponível em: https://www.bbc.com/portuguese/brasil-57208131. Acesso em: 24, jun., 2021. OXFAN. Poder, lucros e a pandemia. Oxfan Internacional, setembro de 2020. Disponível em:https://d335luupugsy2.cloudfront.net/ cms\%2Ffiles\%2F115321\%2F1599751979Poder_Lucros_e_a_Pandemia_-_completo_editado_-_pt-BR.pdf. Acesso em: 01, out. 2020. RAQUEL, M. Quem são as pessoas que não têm acesso à internet no Brasil? Uma a cada cinco pessoas não tem internet própria e compartilha rede do vizinho. Brasil de Fato, São Paulo,10 ago. 2020. Disponível em: https://www.brasildefato.com.br/2020/08/10/ quem-sao-as-pessoas-que-nao-tem-acesso-a-internet-no-brasil. Acesso em: 8, nov. 2020.

ROCHA, Cláudio Jannoti, . 4a Revolução Industrial, cyberização do trabalho, trabalho e sociedade com Cláudio Jannotti da Rocha. Fórum de Debates e Entrevistas: Saúde do trabalhador e da Trabalhadora e Serviço Soicial. Disponível em: <https://www.youtube. com/watch?v=ZaxrH7Tmkpc\&t=1587s>. Acesso em: 04, jun. 2021.

SCHWAB, K. A Quarta Revolução Industrial. 1. ed. São Paulo: Edipro, 2016.

SOUZA, Edvânia Ângela de. A pandemia de COVID-19 e o teletrabalho na Previdência Social (PS). Caderno CRH, volume 34, 2021, no prelo.

SOUZA, Edvânia Ângela de. ANUNCIAÇÃO, Luís. Narrativas de sofrimento e trabalho profissional do Serviço Social da Previdência Social em Tempos de Indústria 4.0. Serviço Social e Sociedade. São Paulo, n. 138 (maio-ago./2020), p.2015-241.

TEMPOS Modernos. Direção de Charlie Chaplin. New York: Charlie Chaplin Film Corporation, 1933.

TURING, A. M. Computing machinery and intelligence. Revista Mind: Oxônia, Reino Unido, n. 49, p. 433-460. Disponivel em: https:// www.csee.umbc.edu/courses/471/papers/turing.pdf. Acesso em: 02, dez. 2020. 
VOCÊ Não Estava Aqui. Direção de Ken Loach. Reino Unido: Sixteen Films, 2019.

ZUBOFF, S. Big Other: capitalismo de vigilância e perspectiva para uma civilização de informação. BRUNO, F.; CARDOSO, B.; KANASHIRO, L. G; MELGAÇO, L (Orgs). Tecnopolíticas da Vigilância: perspectivas da margem. São Paulo: Boitempo, 2018, p. $17-68$.

\section{Notas}

1 Este texto é parte de um projeto de pesquisa que visa discutir as condições de trabalho e saúde de assistentes sociais que atuam na seguridade social no Brasil. O projeto conta com a participação de pesquisadores e pesquisadoras de três universidades públicas: Faculdade de Ciências Humanas e Sociais (Unesp-Franca), Universidade Federal do Pará (UFPA) e Universidade Federal do Rio Grande do Sul (UFRGS), sendo as respectivas coordenadoras de cada região as professoras doutoras Edvânia Ângela de Souza (Unesp-Franca), Vera Gomes, Daniela Castilho, Welson Cardoso (UFPA), Jussara Mendes, Dolores Sanches Wünsch e Tatiana Reidel (UFRGS). Este projeto também fez parte das atividades de pós-doutorado, desenvolvido no período de 2015 a 2017 no Programa de Pós-Graduação em Saúde Coletiva da Unifesp, sob a supervisão do Prof. Dr. Francisco Antônio de Castro Lacaz. Atualmente, foi submetido e aprovado na modalidade Bolsa Produtividade (PQ), sendo aprovado sob o n. 313708/2018.

\section{Edvânia Ângela de Souza}

edvaniaangela@hotmail.com

Doutora em Serviço Social pelo Programa de Pós-Graduação em Serviço Social da Faculdade de Ciências Humanas e Sociais (UNESP-Franca)

Pós-doutora em Saúde Coletiva pelo Programa de Pós-graduação em Saúde Coletiva junto ao Departamento de Medicina Preventiva da Escola Paulista de Medicina (UNIFESP-SP)

\section{FCHS/ UNESP}

Departamento de Serviço Social.

Endereço: Avenida Eufrásia Monteiro Petráglia, n. 900

Jardim Antônio Petráglia

Franca/SP - Brasil

CEP: $14409-160$

\section{Agradecimentos}

Agradecimento às e aos assistentes sociais que tão prontamente aceitaram participar dessa pesquisa e contribuíram para a construção do presente estudo e também às alunas e alunos, bolsistas PIBIC, que tanto colaboraram para que essa pesquisa pudesse ser realizada.

Agência financiadora

CNPQ- Bolsa Produtividade, n. 313708/2018, período: 20182020.

Contribuições das autoras

Não se aplica.
Aprovação por Comitê de Ética e consentimento para participação

Projeto de Pesquisa aprovado pelos Comitês de Ética da UNESP - Franca e da Unifesp,SP. respectivamente sob os números 33447814.6.0000.5408 e 37608314.7.0000.5408.

\section{Consentimento para publicação}

Estou em total acordo com a publicação desse texto pela revista Katályses.

Conflito de interesses

Não há conflitos de interesses. 